\title{
BANGLADESH BETAR'S FARM PROGRAMS TO MOTIVATE FARMERS: AN ANALYSIS OF EFFECTIVENESS AS DISTANCE EDUCATION
}

\author{
Dr. Mahedi HASAN \\ ORCID: 0000-0003-2648-0746 \\ Department of Accounting and Information Systems \\ Jessore University of Science and Technology \\ Jessore, Bangladesh \\ Dr. Nazrul Islam MONDAL \\ ORCID: 0000-0001-7550-7226 \\ Department of Population Science and Human Resource Development \\ University of Rajshahi \\ Rajshahi, Bangladesh
}

Received: 08/08/2018 Accepted: 12/11/2018

\begin{abstract}
Bangladesh Betar (BB), the national radio of Bangladesh has been providing extension services to the mostly uneducated Bangladeshi farming communities for the diffusion of modern farm technologies from its very beginning. This study aimed at evaluating the effectiveness of farm programs (FPs) of BB as distance education through assessing its capacity to motivate the farmers. A sample of 465 farmers was surveyed for primary data and the binary logistic regression model was used for data analysis. This study has revealed that those who listen to the FPs of BB were found more likely to adopt modern farm technologies than those who did not listen to the FPs. The concerned authority should take the necessary steps to make the farmers listen to the FPs of BB for educating and motivating them.
\end{abstract}

Keywords: Bangladesh Betar, farmers of Bangladesh, farm programs, distance education, farm technologies.

\section{INTRODUCTION}

Radio is a powerful and popular audio media conveys message from one station to all. It is a fascinating medium among the various mass communication media because of its special characteristics. It continues to be as relevant and potent as it was in the early years despite the emergence of more glamorous media. It is a truism that in the first phase of broadcasting spanning three decades from the early twenties, radio reigned alone or was the dominant player. Bangladesh Betar (BB) (The National Radio of Bangladesh) is the largest electronic mass media in Bangladesh with the biggest infrastructure covering the whole of Bangladesh. It is the only media that can reach everywhere from solitary villages to the impassable hill tracts and from deep forest to deep sea. Agriculture is one of the most emphasized sectors of BB because Bangladesh is a country of an agrarian economy. Bangladesh is mainly a rural based agricultural country with an area of 1,47,570 square kilometer. The development of Agriculture is mostly dependent on the use of modem technologies by the farmers. About $23.08 \%$ of the country's Gross Domestic Product (GDP) and 62\% of the employment opportunity comes from agriculture (BBS, 2005). Agriculture dominates the economy of Bangladesh by providing food, employment, income and foreign exchange (Hasan et al., 2016). But, a recent study showed that almost all of the farmers (88.94\%) bear poor knowledge of agriculture (Hasan et al., 2017). This is why the farm programs (FPs) of BB are designed and aired for the development of the whole agriculture and the 
farming communities of Bangladesh. Because the basic function of the FPs of BB is to provide extension services to the farmers. The main function of extension is to assist transfer of appropriate technologies to farmers (Kashem, Halim \& Rahman, 1992). And for this reason radio has been the medium used most extensively in developing societies over the past several decades as a cost-effective means of providing information and education to diverse target groups (Mclean, 1992). There is considerable support for the view that radio is an effective medium of instruction (Nwaerondu \& Thomson, 1987). In many countries farm radio forums have been proven to be very successful. Farm radio forums as agents for the transmission of knowledge have proven to be a success beyond expectation (Mathur \& Neurath, 1959), while radio cuts across any literacy barriers (Ani and Baba, 2009; Ariyo et al., 2013). In a recent study by Hasan, et al. (2017a) while assessing for a strong level of knowledge, it was seen that the percentage of listeners of the FPs of $\mathrm{BB}$ was almost seven times higher than the non-listener group.

Bangladesh is supplying to meet the basic needs of her population from its net cultivable land which is estimated around 8.29 million hectare but still perhaps agricultural productivity of this country is one of the lowest in the world. However, the agricultural production can be increased if appropriate technologies are used by the farmers who are the primary unit of adoption of improved farm practices. The BB along with different government agencies, have been trying from the very beginning to educate farmers in Bangladesh about different farm technologies (Hasan et al., 2017). The BB in collaboration with other agricultural departments does this job because multi-channel communication is more effective than single channel communication (Rogers, Braun \& Wermilion, 1975). Besides, radio is used as an effective medium to instill a motivation, collaboration, and development skills needed, as well government plan and agenda to the masses (Yusof, Ibrahim \& Wan, 2012). Most farmers in every sector of agriculture are unaware of the existence, use, and benefits of modern technologies for farming (Hasan et al., 2017a). These gaps in farming knowledge can be better addressed by radio as there is considerable support for the view that radio is an effective medium of instruction (Nwaerondu \& Thomson, 1987).

As the FPs of $\mathrm{BB}$ demonstrate the very qualities of a good program needed to disseminate the correct information to the right people, the FPs of BB should be effective in motivating the farmers. There are some studies in Bangladesh where BB was rated based on the extent to which it was used as an information source (BBS, 2011; Kashem, Halim, \& Rahman, 1992; Kashem \& Poddar, 2000; Kashem \& Islam, 2001) and how effectively it conveyed the information (Amin, 2010). However, there is no sound study on the effectiveness of BB in motivating the farmers. Therefore, this study aimed to evaluate the effectiveness of FPs of BB as distance education in motivating the farmers about farm technologies.

\section{DATA AND METHODS}

\section{Sources of Data}

By dint of document analysis and sample survey data were collected from both the primary and secondary sources. In case of document analysis, document of BB and other relevant organizations were analyzed. By means of questionnaire survey technique, primary data were collected from the sampled farmers.

The BB has twelve regional stations and all the stations have their own customized FPs whose formats and contents are set by the Head Office of BB. So, a single station of BB can epitomize the whole of BB in case of FPs. The BB Khulna, and BB Rajshahi have been purposively selected for this study. The BB Khulna covers Khulna District and BB Rajshahi covers the Rajshahi District. Thus, the study field covers both Khulna and Rajshahi Districts. Using a multistage stratified sampling technique firstly eight upazillas (sub-districts) were selected from the two districts (four from each district). Secondly, eight unions (the smallest local government units) were selected from eight upazillas (one from each upazilla) and thirdly, sixteen villages (two from each union) were selected. At the 4th stage, using random sampling technique, final respondents (farmers: crop, livestock, fisheries) were selected from each village and finally, the total sample size was determined (Figure1). 


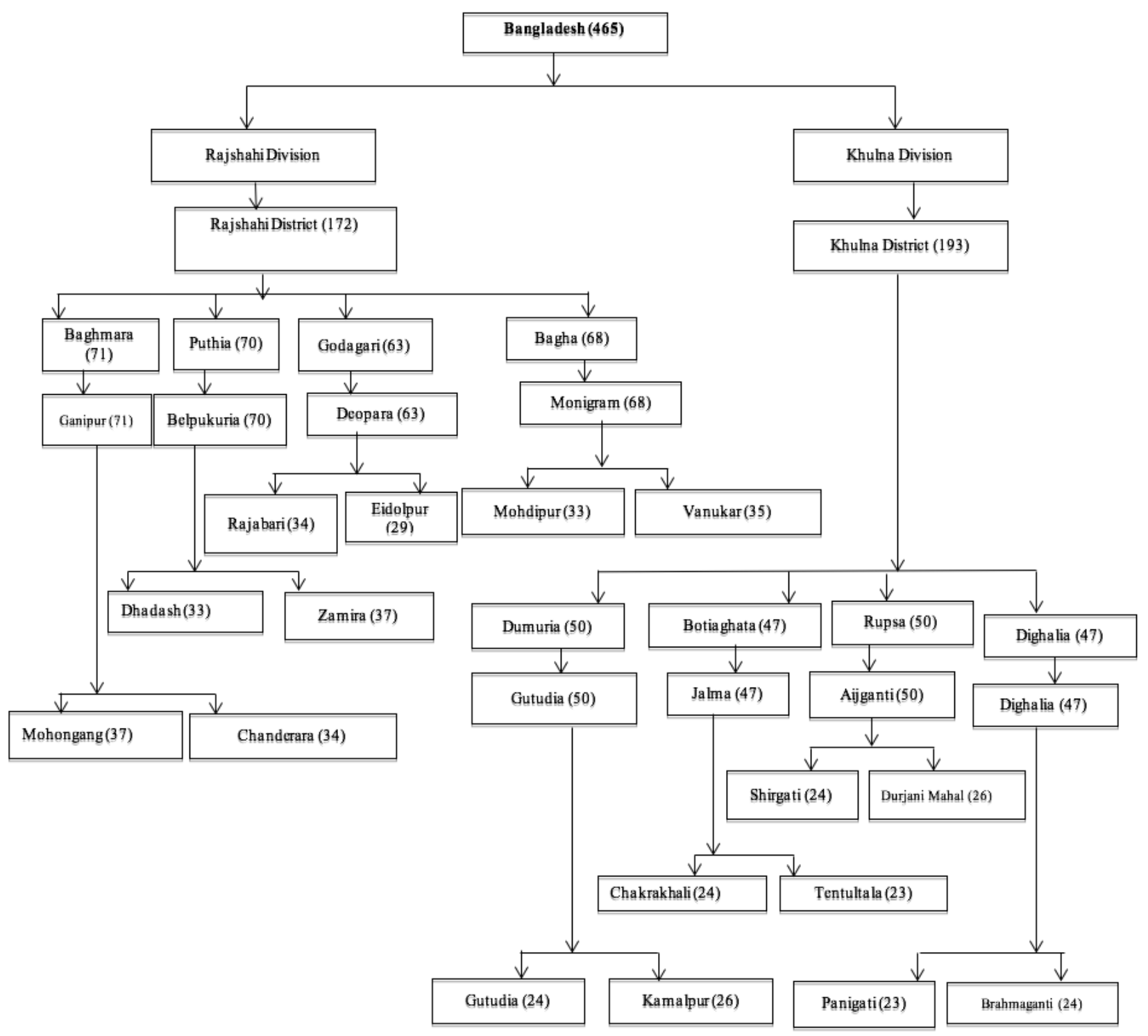

Figure 1. Sampling flowchart

Note: The number inside the parenthesis indicates the number of respondents

The sample size was calculated using a single proportion formula by using $95 \%$ confidence interval (CI), margin of error $5 \%$ and $10 \%$ non-response rate were added to compute the total sample size. In this regard, Cochran (1963) developed the formula to yield a representative sample for proportions:

$$
n=Z^{2} \frac{p(1-p)}{e^{2}}
$$

which is valid where $\mathrm{n}$ is the sample size, $\mathrm{e}$ is the desired level of precision, $\mathrm{p}$ is the estimated proportion of an attribute that is present in the population. The value for $\mathrm{Z}$ is found in statistical tables which contain the area under the normal curve. In this study, are considered.

According to this formula, 384 respondents from the two districts need to be surveyed. But for the betterment of this study 465 respondents were selected from the two study areas and the area and sector-wise sampling are presented in Table 1. 
Table 1. Area and sector-wise sample sizes of the farmers and listeners of FPs of BB

\begin{tabular}{lllll}
\hline Farming Sectors & $\begin{array}{l}\text { Number of farmers in } \\
\text { Khulna }\left(\mathbf{n}_{\mathbf{1}}\right)\end{array}$ & $\begin{array}{l}\text { Number of farmers in } \\
\text { Rajshahi }\left(\mathbf{n}_{\mathbf{2}}\right)\end{array}$ & Total & FPs Listeners (\%) \\
\hline Crop & 81 & 191 & 272 & $17(6.25)$ \\
Livestock & 33 & 42 & 75 & $6(8.00)$ \\
Fisheries & 79 & 39 & 118 & $8(6.78)$ \\
\hline Total & 193 & 272 & $\mathrm{n}=465$ & $31(6.67)$ \\
\hline
\end{tabular}

Note: 'FPs, farm programs', 'BB, Bangladesh Betar'

\section{Data Collection}

A survey was conducted from June to September 2014 to collect primary data relevant to the study objective from 465 farmers. Secondary data were collected using a content analysis technique from the documents of $\mathrm{BB}$ and other relevant organizations viz. Ministry of Agriculture and, Ministry of Fisheries and Livestock.

\section{Data Analysis}

To analyze data frequency distribution followed by z-test and binary logistic regression analysis were conducted. Groups were formed with 272, 75, and 118 farmers respectively from crop, livestock, and fisheries sector. Farmers of each sector were then divided into listener (coded 1) and non-listener (coded $0)$ groups. Some regularly broadcast scientific practices (10,9 and 7 types of scientific practices for crop, livestock and fisheries, respectively) were selected for a comparative analysis between the groups (listener and non-listener) of FPs of BB.

The scientific farm technologies (sector-wise) which the farmers of the respective sectors are taught about through the FPs of BB are as follows:

\section{Crop Sector}

Integrated pest management (IPM), using balanced fertilizer, using Guti urea, using pesticides scientifically, using scientific seedbeds, harvesting seeds separately, irrigation at a critical moment, using organic fertilizer, drying seeds at times, examining the soil for using fertilizers.

\section{Livestock Sector}

Using anthelmintic regularly, artificial insemination for cows, cleaning dwelling places, giving vaccine to the cows before rainy season, feeding urea molasses straw, giving vaccine to chicken regularly, drying grass before feeding in the rainy season, separating the sick animals from others, and burying the dead animals.

\section{Fisheries Sector}

Water purification, using lime for keeping water fresh and fish healthy, maintaining the food-ratio, examining health of fish timely, maintaining fish number, separating the infected fish from others, and seeking doctor's suggestions during diseases.

The different types of radio programs (discussion, talk, drama, songs, etc.) are taken for dissemination of the farm technologies and for the motivation of the farmers. Sometimes successful farmers of different sectors are invited to the programs to discuss about their scientific practices in farming for the motivation of the farmers.

A frequency distribution of the responses of the farmers was conducted to check whether they follow the scientific farm practices or not. Each positive response was coded ' 1 ' and otherwise ' 0 '. Then the significance test (z-test) of the differences was conducted. In the simple binary logistic regression models, scientific farm practices $\left(Y_{i}, i=1,2,3,4,5,6,7,8,9\right)$ were treated as the dependent variables and classified in the following manners: 


$$
Y_{i}=\left\{\begin{array}{l}
0, \text { low } ; \\
1, \text { high } ;
\end{array}\right.
$$

where $i=1,2,3,4,5,6,7,8,9$.

The significant factors in z-test, were considered as the predictors of simple binary logistic regression analysis. The results of binary logistic regression models were presented as odds ratios (ORs) with 95\% CI for easy understanding of the effects of the associated factors on scientific farm practices. Statistical Package for Social Sciences (SPSS) version 17.0 (SPSS Inc., Chicago, IL; USA) and STATISTICA 8 were used for data analysis.

\section{RESULTS}

The study results revealed that the farmers were mostly habituated to unscientific farm practices. The BB usually designed the FPs with a view to persuading the farmers to adopt the scientific technologies in farming and to relieve their adverse mindset towards the experts and farm technologies. It was observed that in the crop sector, out of 272 farmers only 17 (6.25\%) farmers listened to the FPs (Table 1). This study has also divulged that in the comparison between the listeners and non-listeners of FPs the scientific practice acceptance rate is high among the farmers who listen to the FPs (Table 2).

Table 2. Significance test of difference of proportions of farm practices in the crop sector

\begin{tabular}{|c|c|c|c|c|}
\hline Farm practices & Listening FPs & Number of farmers (n) & Practicing Farmers (\%) & p-values \\
\hline \multirow{2}{*}{$\begin{array}{l}\text { Integrated pest } \\
\text { management }\end{array}$} & No & 255 & $25(09.80)$ & \\
\hline & Yes & 17 & $4(23.52)$ & 0.057 \\
\hline \multirow[t]{2}{*}{ Using balanced fertilizer } & No & 255 & $16(6.27)$ & \\
\hline & Yes & 17 & $4(23.52)$ & 0.009 \\
\hline \multirow[t]{2}{*}{ Using Guti urea } & No & 255 & $13(5.09)$ & \\
\hline & Yes & 17 & $5(29.41)$ & 0.000 \\
\hline \multirow{2}{*}{$\begin{array}{l}\text { Using pesticides } \\
\text { scientifically }\end{array}$} & No & 255 & $38(14.90)$ & \\
\hline & Yes & 17 & $6(35.29)$ & 0.028 \\
\hline \multirow[t]{2}{*}{ Using scientific seedbeds } & No & 255 & $24(9.41)$ & \\
\hline & Yes & 17 & $4(23.52)$ & 0.055 \\
\hline \multirow{2}{*}{$\begin{array}{l}\text { Harvesting seeds } \\
\text { separately }\end{array}$} & No & 255 & $102(40)$ & \\
\hline & Yes & 17 & $12(70.58)$ & 0.0149 \\
\hline \multirow{2}{*}{$\begin{array}{l}\text { Irrigation at a critical } \\
\text { moment }\end{array}$} & No & 255 & $6(2.35)$ & \\
\hline & Yes & 17 & $1(5.88)$ & 0.382 \\
\hline \multirow[t]{2}{*}{ Using organic fertilizer } & No & 255 & $184(72.15)$ & \\
\hline & Yes & 17 & $12(70.58)$ & 0.889 \\
\hline \multirow[t]{2}{*}{ Drying seeds at times } & No & 255 & $138(54.11)$ & \\
\hline & Yes & 17 & $10(58.82)$ & 0.704 \\
\hline \multirow{2}{*}{$\begin{array}{l}\text { Examining the soil for } \\
\text { using fertilizers }\end{array}$} & No & 255 & $4(1.56)$ & \\
\hline & Yes & 17 & $0(0.00)$ & 0.596 \\
\hline
\end{tabular}

Note: 'FP, farm programs'

In the significant tests, it was seen that in most of the cases (IPM, using balanced fertilizer, using Guti urea, using pesticides scientifically, using scientific seedbeds, and harvesting seeds separately) of scientific practices in a crop sector the differences between the listeners and non-listeners were quite significant $(\mathrm{p}<0.05)$. In the logistic regression model, it was seen that in case of crop sector if a farmer listened to the FPs, he/she was more likely to adopt scientific farm technologies- IPM, using balanced fertilizers, using Guti urea, using pesticides scientifically, harvesting seeds separately, using scientific seedbeds were 2.962 times (OR: 2.962; 95\% CI: 0.895-9.802), 4.596 times (OR: 4.596; 95\% CI: 1.344-15.719), 7.756 times (OR: 7.756; 95\% CI: 2.376-25.321), 3.316 times (OR: 3.316; 95\% CI: 1.138-9.662), 3.553 times (OR: 3.553; 95\% CI: 1.215-10.390), 2.962 times (OR: 2.962; 95\% CI: 0.895-9.802) respectively than the farmers who did not listen to the FPs (Table 3). 
Table 3. Effects of farm programs of Bangladesh Betar on the farm practices in the farmers

\begin{tabular}{|c|c|c|c|c|c|c|c|c|}
\hline \multirow{2}{*}{$\begin{array}{l}\text { Farm } \\
\text { sectors }\end{array}$} & \multirow[t]{2}{*}{ Scientific practices } & \multirow{2}{*}{$\begin{array}{l}\text { Characteristic } \\
\text { Listening the FPs }\end{array}$} & \multirow{2}{*}{$\begin{array}{l}\text { Coefficient } \\
\text { ( } \beta)\end{array}$} & \multirow{2}{*}{$\begin{array}{l}\text { SE } \\
(\beta)\end{array}$} & \multirow[t]{2}{*}{$p$-values } & \multirow{2}{*}{$\begin{array}{l}\text { Odds ratio } \\
\text { (OR) }\end{array}$} & \multicolumn{2}{|c|}{$95 \% \mathrm{Cl}$ for OR } \\
\hline & & & & & & & Lower & Upper \\
\hline \multirow{12}{*}{ Crop } & Integrated pest & Do not listen $(r)$ & & & & 1.00 & & \\
\hline & management & Listen & 1.086 & 0.611 & 0.075 & 2.962 & 0.895 & 9.802 \\
\hline & Using balanced & Do not listen $(r)$ & & & & 1.00 & & \\
\hline & fertilizer & Listen & 1.525 & 0.627 & 0.015 & 4.596 & 1.344 & 15.719 \\
\hline & \multirow{2}{*}{ Using Guti urea } & Do not listen $(r)$ & & & & 1.00 & & \\
\hline & & Listen & 2.049 & 0.604 & 0.001 & 7.756 & 2.376 & 25.321 \\
\hline & Using pesticides & Do not listen $(r)$ & & & & 1.00 & & \\
\hline & scientifically & Listen & 1.199 & 0.546 & 0.028 & 3.316 & 1.138 & 9.662 \\
\hline & Harvesting seeds & Do not listen $(r)$ & & & & 1.00 & & \\
\hline & separately & Listen & 1.268 & 0.548 & 0.021 & 3.553 & 1.215 & 10.390 \\
\hline & \multirow{2}{*}{$\begin{array}{l}\text { Using scientific } \\
\text { seedbeds }\end{array}$} & Do not listen $(r)$ & & & & 1.00 & & \\
\hline & & Listen & 1.086 & 0.611 & 0.075 & 2.962 & 0.895 & 9.802 \\
\hline \multirow{6}{*}{ Livestock } & Using anthelmintic & Do not listen $(r)$ & & & & 1.00 & & \\
\hline & regularly & Listen & 1.931 & 1.122 & 0.085 & 6.897 & 0.764 & 62.217 \\
\hline & Cleaning dwelling & Do not listen $(r)$ & & & & 1.00 & & \\
\hline & places & Listen & 2.369 & 1.125 & 0.035 & 10.682 & 1.177 & 96.976 \\
\hline & \multirow{2}{*}{$\begin{array}{l}\text { Vaccinate the } \\
\text { chicken regularly }\end{array}$} & Do not listen $(r)$ & & & & 1.00 & & \\
\hline & & Listen & 1.891 & 0.912 & 0.038 & 6.625 & 1.109 & 39.565 \\
\hline
\end{tabular}

Note: ' $R$, the reference category', 'CI, the confidence interval'

In the livestock sector, $8 \%$ (only 6 out of 75 ) farmers listen to the farm programs (Table 1 ). The study also revealed that in the comparison between the listeners and non-listeners of FPs of BB the scientific practice adoption rate is high among the farmers who listen to the FPs of BB (Table 4).

Table 4. Significance test of the difference of proportions of farm practices in the livestock sector

\begin{tabular}{|c|c|c|c|c|}
\hline Farm practices & Listening FPs & Number of farmers $(n)$ & Practicing Farmer (\%) & $p$-values \\
\hline \multirow[t]{2}{*}{ Using anthelmintic regularly } & No & 69 & $29(42.00)$ & \\
\hline & Yes & 6 & $5(83.33)$ & 0.055 \\
\hline \multirow[t]{2}{*}{ Artificial Insemination } & No & 58 & $31(53.44)$ & \\
\hline & Yes & 5 & $4(80.00)$ & 0.250 \\
\hline \multirow[t]{2}{*}{ Cleaning dwelling places } & No & 69 & $22(31.90)$ & \\
\hline & Yes & 6 & $5(83.33)$ & 0.014 \\
\hline \multirow[t]{2}{*}{ Vaccinate before rainy season } & No & 65 & $23(35.38)$ & \\
\hline & Yes & 6 & $4(66.67)$ & 0.131 \\
\hline \multirow[t]{2}{*}{ Feeding urea molasses straw } & No & 58 & $7(12.06)$ & \\
\hline & Yes & 5 & $2(40.00)$ & 0.087 \\
\hline \multirow[t]{2}{*}{ Vaccinating the Chickens Regularly } & No & 54 & $16(29.63)$ & \\
\hline & Yes & 5 & $4(80.00)$ & 0.022 \\
\hline \multirow{2}{*}{$\begin{array}{l}\text { Drying grass before feeding in the } \\
\text { rainy season }\end{array}$} & No & 58 & $9(15.51)$ & \\
\hline & Yes & 5 & $1(20.00)$ & 0.795 \\
\hline \multirow{2}{*}{$\begin{array}{l}\text { Separating the sick animals from the } \\
\text { others }\end{array}$} & No & 69 & $45(65.22)$ & \\
\hline & Yes & 6 & $6(100.00)$ & 0.080 \\
\hline \multirow[t]{2}{*}{ Burying the dead animals } & No & 69 & $37(53.62)$ & \\
\hline & Yes & 6 & $5(83.33)$ & 0.795 \\
\hline
\end{tabular}

Note: 'FP, farm program' 
In the significant tests, it was seen that in most of the cases (using anthemintic regularly, cleaning dwelling places, and vaccinate the chickens regularly) of scientific farm practices the differences between the listeners and non-listeners were quite significant $(\mathrm{p}<0.05)$. In the logistic regression model, it was seen that if a farmer listened to the FPs, he/she was more likely to adopt scientific farm technologies-Using anthelmintic regularly, Cleaning dwelling places, vaccinate the chicken regularly were 6.897 times (OR: 6.897; 95\% CI: 0.764-62.217), 10.682 times (OR: 10.682; 95\% CI: 1.177-96.976), 6.625 times (OR: 6.625; 95\% CI: $1.109-39.565)$ respectively than the farmers who did not listen to the FPs (Table 3).

In the fisheries sector, $6.78 \%$ (only 8 out of 118) farmers listen to the FPs of BB (Table 1). The study also revealed that in the comparison between the listeners and non-listeners of FPs of BB, the scientific farm practice adoption rate is found higher among the farmers who listen to the FPs (Table 5). In the significant tests, it was seen that in most of the cases of scientific practices the differences between the listeners and non-listeners were not significant. But the fact is that the listeners are motivated more to accept the new scientific farm technologies.

Table 5. Significance test of difference of proportions of farm practices in the fisheries sector

\begin{tabular}{|c|c|c|c|c|}
\hline Farm practices & Listening FPs & Number of Farmers $(n)$ & Practicing farmer (\%) & $p$-values \\
\hline \multirow[t]{2}{*}{ Water purification } & No & 110 & $93(84.54)$ & \\
\hline & Yes & 8 & $8(100.00)$ & 0.2311 \\
\hline \multirow{2}{*}{$\begin{array}{l}\text { Using lime for keeping water fresh } \\
\text { and fish healthy }\end{array}$} & No & 110 & $16(14.56)$ & \\
\hline & Yes & 8 & $2(25.00)$ & 0.4263 \\
\hline \multirow[t]{2}{*}{ Maintaining the food-ratio } & No & 110 & 18(16.36) & \\
\hline & Yes & 8 & $2(25.00)$ & 0.5329 \\
\hline \multirow[t]{2}{*}{ Examining health of fish timely } & No & 110 & $77(70.00)$ & \\
\hline & Yes & 8 & $7(87.50)$ & 0.2935 \\
\hline \multirow[t]{2}{*}{ Maintaining fish number } & No & 110 & $9(8.18)$ & \\
\hline & Yes & 8 & $0(0.00)$ & 0.4009 \\
\hline \multirow{2}{*}{$\begin{array}{l}\text { Separating the infected fish from } \\
\text { others }\end{array}$} & No & 110 & $80(72.73)$ & \\
\hline & Yes & 8 & $8(100.00)$ & 0.08186 \\
\hline \multirow{2}{*}{$\begin{array}{l}\text { Seeking doctor's suggestions } \\
\text { during diseases }\end{array}$} & No & 110 & $47(42.73)$ & \\
\hline & Yes & 8 & $6(75.00)$ & 0.07672 \\
\hline
\end{tabular}

Note: 'FP, farm program'

\section{DISCUSSION}

The objective of the study was to reveal the effectiveness of FPs of BB in motivating the farmers to adopt the scientific farm practices. It was seen that in most of the cases the farmers who listened to the FPs tried to follow the scientific practices more than that of the farmers who did not listen to the FPs. It means, the FPs were effective in motivating the farmers to adopt the scientific technologies in farming and this finding agrees with the previous studies of many researchers (Jain, 1987; Piotrow et al., 1992, etc.). The reason behind this finding might be that the farm programs are Ashor based (a format of FP) discussion programs where there are some actors along with the expert who discusses on a certain topic of scientific farm technologies in local vernacular where their conversation was inspirational and in some programs successful farmers of any sector present the success stories which might act as a motivational force. In comparison among the sectors (crop, livestock, and fisheries) it was seen that the fisheries and livestock farmers are less motivated than the crop farmers. The reason behind this might be that fewer programs on livestock and fisheries are broadcast in comparison with the crop sector. The study result revealed that only one day per week is fixed for each of the two sectors (livestock and fisheries) whereas programs on crop sector were broadcast four days per week. Even the mindset of the farmers who listen to the farm programs shaped up better than that of the farmers who do not listen to the FPs. This result is in agreement with those of the studies (Jain 1987; Sasidhar, Majumdar \& Garg, 2008; Heong et al., 2008). The reason behind this finding might be that after listening to the FPs of BB they could make a comparison between the information they got from FPs and what the field level experts suggested. When the experts' suggestion matched with the information got from FPs they got motivated. This study revealed that the FPs have the ability to motivate the farmers. 
In this study, it was also seen that many of the farmers who do not listen to the FPs of BB deserve negative mindset towards the government experts. A vast majority of the respondents considered that the experts especially the Agriculture Officers and Fisheries Officers do not know anything. Even some of the farmers thought that if they follow the suggestions of those experts, they would be at stake and that is why they used to do everything according to their own indigenous farm knowledge. But, none of the farmers who listen to the FPs made any adverse comments about the experts and modern technologies. This is a clear indication of the effectiveness of the FPs of BB in changing the mindset of the farmers and motivating them thereby.

The limitation of the study is that the study is confined to crop, fisheries and livestock sectors and the forest sector is deliberately excluded for time and economic restraints. Another limitation of the study is that out of eight divisions only Rajshahi and Khulna were selected as the study areas. There may be further studies on developing a listener-driven marketing strategy, finding out the device which is culturally fit to convey the FPs to the farmers and so on for accelerating the extension services.

\section{CONCLUSION}

The research findings divulge that in every sector the farmers who listen to the FPs of BB are more aware of the modern technologies for farming and are more likely to adopt the new farm technologies more than the farmers who do not listen to the FPs of BB. So, it implies that the FPs of BB are effective to motivate the farmers in adopting the modern farm technologies. Even there is a positive change in the mindset of the farmer who listens to the FPs better than that of the farmer who does not listen to the FPs. This is why the concerned authorities should take necessary steps to make the farmers listen to the FPs of BB for the betterment of their farming.

\section{BIODATA and CONTACT ADDRESSES of AUTHORS}

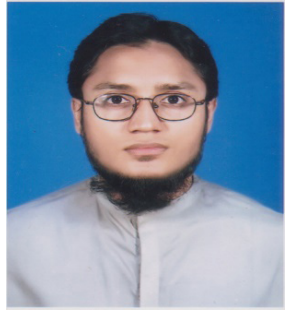

Dr. Mahedi HASAN, is an Assistant Professor in the Department of Marketing, Jessore University of Science and Technology; Bangladesh. He has worked as the Program Organizer of Bangladesh Betar, the National Radio of Bangladesh for several years. Dr. Hasan has gained his PhD in Educational Technology in 2015. His academic interest areas are marketing, media analysis, and motivation. By this time he has published 9 research articles in home and abroad.

\section{Mahedi HASAN}

Address: Department of Marketing Faculty of Business Studies Jessore University of Science and Technology, Jessore 7408; Bangladesh Phone: +88-01711111817

E-mail: mahedimkt@just.edu.bd

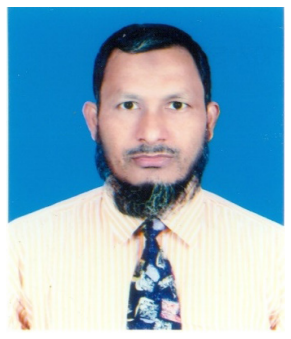

Dr. Nazrul Islam MONDAL, is a Professor in the Department of Population Science and Human Resource Development at the University of Rajshahi in Bangladesh. Dr. Mondal has gained his Ph.D. in Demography in 2002. His research and teaching areas include Population Modeling, Demographic and Public Health Issues, Education, and Sustainable Development. He has over than 90 journal articles published in international indexes, 2 international book chapters and other national and international articles, papers submitted to international meetings.

Nazrul Islam MONDAL

Address: Department of Population Science and Human resource Development University of Rajshahi, Rajshahi 6205; Bangladesh Phone: +88-01716922856 E-mail: nazrulupm@gmail.com 


\section{REFERENCES}

Amin, M. R. (2010). Effectiveness of Radio and Television Program in the Disseminating Agricultural Information as Perceived by the Farmers of Sadar Upazila under Sylhet District. Department of Agronomy and Agricultural Extension, University of Rajshahi; Bangladesh (Unpublished Ph. D. Dissertation).

Ani, A. O., \& Baba, S. A. (2009). Utilization of Selected Electronic Mass Media as Sources of Agricultural Information by Farmers in Northern Taraba State. Nigeria. Tropical Agricultural Research \& Extension, 12, 17-22.

Ariyo, O. C., Ariyo, M. O., Okelola, O. E., Aasa, O. S., et al. (2013). Assessment of the Role of Mass Media in the Dissemination of Agricultural Technologies among Farmers in Kaduna North Local Government Area of Kaduna State, Nigeria. Journal of Biology, Agriculture and Healthcare, 3, 19-28.

B. B. S. (2005). Statistical Year Book of Bangladesh. Bangladesh Bureau of Statistics. Ministry of Planning, Government of the People's Republic of Bangladesh.

B. B. S. (2011). Report on the Bangladesh Literacy Survey, 2010. Bangladesh Bureau of Statistics (BBS), Industry and Labor Wing, Statistics Division, Ministry of Planning, Dhaka; Bangladesh.

Cochran, W.G. (1963). Sampling Techniques. 2nd ed., John Wiley and Sons, Inc., New York; USA.

Hasan, M. M., Mondal, M. N. I., Islam, M. N., \& Hoque, M. A. (2016). Fitness of Farm Programs of Bangladesh Betar for Extension Services: A Field Study. Indian Research Journal of Extension Education, 16 (1), 16-24.

Hasan, M. M., Mondal, M. N. I., Islam, M. N., \& Hoque, M. A. (2017). Farmers' Access to Farm Programs of Bangladesh Betar: An Evaluation of Effectiveness. Indian Research Journal of Extension Education, $17(1), 5-12$.

Hasan, M. M., Mondal, M. N. I., Islam, M. N., \& Hoque, M. A. (2017a). The Effectiveness of Farm Programs of Bangladesh Betar in Educating Farmers. Open Learning: The Journal of Open, Distance and e-Learning, 32:3, 214-223. DOI:10.1080/02680513.2017.1345679

Heong, K. L., Escalada, M. M., Huan, N. H., Ky Ba, V. H., et al. (2008). Entertainment-Education and Rice Pest Management: A Radio Soap Opera in Vietnam. Crop Protection, 27, 1392-97.

Jain, N. C. (1987). An Experimental Investigation of the Effectiveness of Commitment and Consensus in India Radio Forum. University Microfilms, 300 N. Zeeb Rd., Ann Arbor, Michigan, 48106; USA.

Kashem, M. A., \& Islam, M. S. (2001). Information Sources used by Farmers Regarding the use of Agrochemicals. Bangladesh Journal of Extension Education, 13, 71-75.

Kashem, M. A., \& Poddar, S. (2000). Communication Behavior of Mehersagar Banana Growers. Journal of Communication Studies, 18, 88-99.

Kashem, M. A., Halim, A. \& Rahman, M. Z. (1992). Farmers' Use of Communication Media in Adopting Agricultural Technologies- Farm Level Study in Bangladesh. Asia-Pacific Journal of Rural Development, II, 1, 94-112.

Mathur, J. C., \& Neurath, P. (1959). Indian Experiment in Farm Radio Forum: Press, Film and Radio in the World Today.United Nations Educational Scientific and Cultural Organization (UNESCO): (Series of studies). Paris: UNESCO: M. Blondin.

Mclean, P. E. (1992). Radio and rural development in Swaziland. Africa Media Review, 6, 51-64.

Nwaerondu, N. G. \& Thomson, G. (1987). The use of educational radio in developing countries: Lessons from the past. Journal of Distance Education, 2, 43-54.

Piotrow, P. T., Kincaid, D. L., Hindin, M. J., Lettenmaier, C. L., et al. (1992). Changing Men’s Attitudes and Behavior: The Zimbabwe Male Motivation Project. Studies in Family Planning, 23 (6), 365-75. 
Rogers, E. M., Braun, J. R. \& Vermilion, M. A. (1975). Radio Forums: A Strategy for Rural Development. Institute for Communication Research, Stanford University; USA.

Sasidhar P. V. K., Majumdar, S. \& Garg, D. C. (2008). An Evaluation of Backyard Poultry Radio Farm School. Indian Journal of Poultry Science, 43 (3), 347-50.

Yusof, F., Ibrahim, F., \& Wan, A. W. (2012). Agricultural radio talks and drama: Malaysia early development experience. Malaysian J. of Communication, 28 (1), 77-88. 